conditions: the required tolerance being about onetenth of the received wave-length measured from a geometric paraboloid. If part of the reflector is beyond such shape tolerances, the efficiency of the instrument is impaired. The shorter the wave-length of operation, the smaller the tolerances permitted. Thus, for $10-\mathrm{cm}$ wave-lengths the reflector surface may not be out of shape by more than $\pm 1 \mathrm{~cm}$.

The accuracy of pointing and tracking required for these very large masses presents entirely new problems. Whereas optical telescopes are mounted on equatorial axes and it would be desirable for radio telescopes to be similarly mounted, the high resulting torques and the necessity for counterweights that practically double the mass to be moved, increase the costs above the more practical alt-azimuth mounting.

Mechanical power transmissions and gear reduction assemblies are easily available items, but the accuracy of control requires some unusual tolerances in machining, while speeds of motion are so slow that now concepts of bearing designs and frictional values are requirerl.

Two somewhat longer chapters discuss design studies for extremely large telescopes. Brief mention is made of some types of fixed reflectors, while the specifications and design procedure for a $600-\mathrm{ft}$. fully steerable paraboloid reflector are described in greater detail. Mr. Feld summarizes his own com- plete design study for a 600 -ft. instrument and suggests that his findings indicate certain trends which should be further examined and evaluated. In a later chapter, describing some instruments in the United States, mention is made of the $600-\mathrm{ft}$. telescope which has been under construction at the U.S. Navy Observatory at Sugar Grove, West Virginia. Con. struction started early in 1959 and completion at an estimated cost of 79 million dollars was scheduled for 1962. However, the design was completely $\mathbf{r} \in$ vised, resulting in indications pointing to a much larger weight to obtain the desired stiffness and accuracy of shape. Corresponding modifications to underearriage, track and foundations, together with considerable increased cost estimates, would have delayed completion until about 1964. Since publication of this paper, cancellation of the whole project has been announced.

Comparative studies of the design of the $140 \mathrm{ft}$. telescope now being constructed at Green Bank, West Virginia, are described in the latter part of this paper, which concludes with a ehapter discussing a number of fixed types of reflector, planned or already in use.

A full list of references, together with a number of illustrations and drawings, complete an interesting and valuable contribution to the limited reading matter available on radio telescopes. R. F. Touson

\title{
GENERAL STUDIES IN TECHNICAL COLLEGES
}

GUIDANCE to technical colleges on the selection $\checkmark$ and treatment of the content of 'general studies' for young craftsmen and technicians are contained in a report published by the Ministry of Education*.

The report has been prepared by an advisory committee set up after the publication of the White Paper, "Better Opportunities in Technical Education". The White Paper stated that, when courses were lengthened to the 330 hours a year recommended by the Crowther Committee, the time given to English and general subjects, including physical education, should be increased. The report recalls the "four strands" of the Crowther Report which outlined the wider social purposes of further education. These were to help young workers to find their way successfully about the world both as consumers and citizens, to form standards of moral values by which they can live in the new world in which they find themselves, to continue and develop the pursuits and activities which they have begun at school and to improve their basic education. The report points out that the first need for the students in both the technical and general elements of their course is to develop their communication skills. They must be able to make themselves understood in speech and writing, and, through listening and reading, to understand other people. Success in their technical subjects directly depends on mastery of these skills; they are essential, too, for the student's development as an individual and as a member of society. It is for these reasons that the teaching of English and general studies should be regarded as a single operation.

The report outlines five broad areas of knowledge and experience from which the subject-matter for

* Ministry of Education. General Studies in Technical Colleges. Pp. ii +23. (London: H.M.S.0., 1962.) 2s. net. general studies might be selected. Some of the many suggestions made, under these main headings, are:

(1) The student and the college-nature and organization of the college; the student's place in it; his relations with staff and fellow students.

(2) The student and his job-training facilities; prospects and ambitions; the student's firm; relations on the shop floor; work, wages, costs and profits; health and safety at work.

(3) The student, his home, his family and his friends - the significance of the human family group in society; relations between the sexes; love, courtship marriage.

(4) The student and the wider community-the local community, its history, industry and places of interest; national Government; the welfare state; discipline and the law; present-day economic problems.

(5) The widening of horizons and the development of personal interests - the universe and man's place in it; concepts of space and time; the practice, study and appreciation of the arts; opportunities to practise handicrafts; physical education and recreation.

The report indicates that this broad scheme is not exhaustive nor is it intended to be a syllabus. It is more a storehouse for which topies might be drawn. Not all the subjects would be covered in class time. Many of the activities and interests should spill over into societies and informal groups with a vigorous life of their own.

An appendix suggests how the general lines of approach may be applied to a specific theme. Four 'theme treatments' are given, all of them examples of courses which have been planned and carried out with day-release students. 